\title{
INVESTIMENTO E FINANCIAMENTO: UM ENFOQUE SOBRE EMPRESAS DE CAPITAL ABERTO(*)
}

\author{
Elton Eustáquio Casagrande \\ Alexandre Sartoris ${ }^{* * *}$
}

\begin{abstract}
RESUMO: O objetivo do artigo é analisar os determinantes do investimento para uma amostra com 334 empresas no Brasil para o período de 1998 a 2000. As empresas foram selecionadas segundo o critério de liquidez acionário através do índice de negociabilidade de 1998 da Bolsa de Valores de São Paulo, que aponta o grau de liquidez das ações. Com isso, procuramos contribuir para o entendimento do financiamento das empresas no Brasil em condições de instabilidade macroeconômica.
\end{abstract}

PALAVRAS-CHAVE: investimento; financiamento; instabilidade.

CLASSIFICAÇÃO JEL: G3.

\section{INVESTMENT AND FINANCING: A STUDY ON BRAZILIAN CAPITAL MARKETS}

\begin{abstract}
This paper analyzes the determinants of investment for a sample of 334 companies in Brazil for the period from 1998 to 2000. The sample was selected according to the criteria of liquidity, based on 1998 Sao Paulo Stock Exchange equity index of merchantability, which indicates the degree of liquidity of shares. We seek to contribute to the understanding of corporate finance in Brazil under conditions of macroeconomic instability.
\end{abstract}

KEYWORDS: investment; financing; instability.

\footnotetext{
*Artigo recebido em 26/01/2011 e aprovado em 18/01/2012.

** Professor Doutor do Departamento de Economia e do Programa de Pós-Graduação em Economia da Unesp - Araraquara. Contato: elton@fclar.unesp.br.

*** Professor Doutor do Departamento de Economia e do Programa de Pós-Graduação em Economia da Unesp - Araraquara. E-mail: asartoris@uol.com.br.
} 


\section{INTRODUÇÃO}

Nos estudos sobre a teoria do investimento tem sido demonstrada a interdependência entre a estrutura de financiamento das corporações e os investimentos produtivos.

Partimos dessa interdependência para identificar e analisar os determinantes dos investimentos das empresas de capital aberto no Brasil no período de 1998 a 2000. Com isso, procuramos contribuir para o entendimento do financiamento das empresas no Brasil em condições de instabilidade macroeconômica ${ }^{1}$. Nossa hipótese é de que as empresas mais negociadas na Bolsa de Valores de São Paulo, no período de 1998 a 2000, recorreram ao financiamento interno, através da acumulação de lucros, para poder continuar seus planos de investimento em face da instabilidade do período.

Dentro da realidade das empresas de capital aberto no Brasil, 1995 foi o primeiro dos dez anos que se seguiram de expansão de vendas e lucros. Desde 1994, as empresas S.A. (Sociedades Anônimas) aumentaram as dívidas, sustentaram o crescimento das vendas, melhoraram suas margens operacionais e aumentaram a capacidade de pagamento. O grau de alavancagem dessas corporações praticamente dobrou com as dívidas em dólar.

A seleção das 334 empresas que compõem a amostra organizada através de dados em painel passou pela aplicação de um critério $a$ priori. $\mathrm{O}$ índice de negociabilidade serviu como critério para distinguir os diferentes comportamentos entre as empresas e, ao mesmo tempo, estar diretamente relacionado com a leitura dos interesses dos investidores na formação de seus "portfólios". A preferência dos investidores pelas empresas do mercado leva-nos à classificação segundo o grau de negociação das ações. Desta forma, conhecendo as empresas mais negociadas, temos a preferência dos investidores em cada ano. A Bolsa de Valores de São Paulo forneceu a composição do índice de negociabilidade das empresas para o ano de 1998, o primeiro do triênio que analisaremos ${ }^{2}$. O índice de negociabilidade é a expressão dos poderes econômico e financeiro de uma firma no mercado de capitais e deve revelar, em princípio, a

\footnotetext{
${ }^{1}$ No período, ocorre a crise de balanço de pagamentos dos países asiáticos (Indonésia, Coreia do Sul, Malásia, Filipinas e Tailândia). O Brasil perdeu cerca de US\$ 10 bilhões de reservas internacionais, o que criou grandes incertezas na economia brasileira. Em 1999, houve a desvalorização cambial que alterou os custos de captação de moeda estrangeira e os custos do crédito interno, dada a incerteza com relação à inflação esperada.

${ }^{2}$ A Bolsa de Valores forneceu o índice de negociabilidade excepcionalmente para um único ano, uma vez que o mesmo é sigiloso. Contudo, a BOVESPA revelou que no período de 1995 a 1999, a composição das 303 empresas mais negociadas foi estável.
} 
capacidade de compatibilizar as oportunidades de investimento com os planos de financiamento.

Além da introdução contida nesta seção 1, na seção 2 do artigo, analisamos os avanços recentes na teoria do investimento que estuda a interação entre os sistemas financeiros e o desempenho das firmas. A análise dos determinantes no nível da firma é importante porque a disponibilidade, as garantias associadas e os custos dos financiamentos influenciam a capacidade de crescimento das empresas segundo as circunstâncias, a tipologia das firmas e as características dos sistemas financeiros. Na seção 3, analisamos o comportamento das firmas do mercado de capitais no Brasil através dos indicadores econômico-financeiros. Na seção 4, estimamos um modelo econométrico, nos moldes da literatura internacional, e identificamos os determinantes do investimento para o período. $\mathrm{Na}$ conclusão, avaliamos os critérios para formar amostras e comparamos os resultados da análise dos indicadores econômico-financeiros com os resultados econométricos.

\section{UM RESGATE SINTÉTICO DA TEORIA DO INVESTIMENTO}

Os modelos empíricos compreendem as técnicas econométricas que explicam o comportamento do investimento. $\mathrm{O}$ uso de modelos econométricos não é frequente nos textos sobre investimento de autores pós-keynesianos, mas serão úteis para reforçar suas argumentações.

Os primeiros estudos da teoria do investimento foram realizados pelos trabalhos de Meyer e Kuh (1957), Meyer e Glauber (1964), e Anderson (1964). Com o teorema Modigliani e Miller (1958, 1961), MM daqui em diante, Jorgenson e seus colaboradores (1968) procuraram demonstrar a superioridade da teoria neoclássica e a consistência interna de seus modelos, que provava a completa independência das decisões de investir e financiar ${ }^{3}$. Essa tese neoclássica implicaria que a forma de financiamento dos investimentos não interferiria no valor da firma ou em suas decisões de investimento.

A demanda por capital na teoria neoclássica é determinada pela igualdade entre os benefícios marginais esperados e o custo de uma unidade adicional de capital. A demanda por investimento inclui um aspecto dinâmico na função, denominado acelerador. O princípio do acelerador faz o investimento ser uma proporção linear das mudanças no produto. $\mathrm{O}$ acelerador tornou-se uma contribuição popularizada, devido

\footnotetext{
${ }^{3}$ Referem-se àqueles que mais propagaram as teses neoclássicas com modelos empíricos de investimento.
} 
principalmente à sua simplicidade: a partir de um incremento na taxa capital-produto, é simples calcular o investimento necessário para atender a uma dada meta de crescimento do produto.

$$
K^{\star}=f \text { [preços, quantidades, choques] }
$$

A partir do acelerador, Jorgenson (1967) e Hall e Jorgenson (1971) formularam a teoria neoclássica do investimento. Em termos práticos, o modelo neoclássico parte da equação (1), utilizando-se de uma estrutura rigorosa para identificar as variáveis explicativas do investimento, especialmente os efeitos dos preços relativos. A firma encontra instantaneamente o estoque ótimo de capital, $K^{\star}$, o qual maximiza seus lucros.

O estoque ótimo de capital depende do preço dos bens de capital, da taxa de juros e da depreciação. Os atrasos, tanto das decisões de investimento, quanto na entrega da encomenda geram a distância entre o volume de capital $K$ corrente e o $K^{\star}$ ótimo. Nesse sentido, o problema de otimização é estático.

According to the Neoclassical model, firms make employment, investment, and production decisions to maximize their profits (more precisely, the present value of profits over time). The only constraints on firms' choice arise from market prices (which they cannot affect under typical, perfectly competitive assumptions) and technology (which determines the amount of output the firm can produce from its choice of employment and capital inputs). In this theoretical framework, investment is determined by technology and the full spectrum of prices. (Fazzari, 1993, p. 15)

A determinação das condições técnicas do investimento levará uma firma a investir em uma nova planta ou na compra de máquinas e equipamentos se o valor de um dado projeto exceder o custo de capital, líquido de impostos. O custo de capital define-se como o custo de oportunidade de um investimento. Esse custo é medido pela taxa de juros ajustada tanto ao risco quanto à inflação futura. Uma elevação da taxa de juros afetaria diretamente o custo de capital e, consequentemente, o volume de investimento. Fatores que elevam a taxa de juros são, portanto, concorrentes ao investimento. A formulação neoclássica apresenta uma equação para testar os determinantes do investimento e, especialmente, os efeitos dos preços relativos. Como resgata Chirinko (1993),

A role for prices, as well as shocks, was introduced informally in The General Theory, where the benefits and costs of acquiring capital were related to the marginal efficiency of capital (i.e., internal rate of return, affected substantially by autonomous shocks) and the interest rate, respectively. (Chirinko, 1993, p. 1878) 
A função neoclássica do investimento tem a seguinte forma:

$$
I t=\delta K t-1+\sum_{j-0}^{J} \alpha \beta j \Delta\left(Y_{t-j} C_{t-j}^{-\sigma}\right)+\mu_{t}
$$

Onde:

It = investimento total;

$\delta=$ depreciação;

$\sigma=$ elasticidade de substituição entre capital e trabalho;

$\alpha=$ parâmetro de distribuição;

$\beta=$ defasagem de entrega do equipamento;

$Y=$ variável quantitativa (vendas);

$C t=$ custo do capital;

$\mu=$ erro.

Esta equação contém algumas modificações desde a elaboração original de Clark (1917). Chirinko (1993) mostra que,

While the dynamics associated with replacement investment follow from explicit assumptions, theory has been practically silent on the distributed coefficients for net investment. In Jorgenson's work, $\mathbf{s}$ was always assumed to be unity, though alternative values are also consistent with the Neoclassical framework (Eisner and N. Ishaq Nadiri 1968). When $\mathbf{s}=0$, (1) reduces to the flexible accelerator (Hollis Chenery 1952) and, when delivery lags are absent, the result is the simple accelerator (John Clark 1917). (Chrinko, 1993, p. 1.878-79) ${ }^{4}$

A aceitação do teorema MM faz o gasto de investimento ser explicado pelas variáveis reais, tais como os preços e a tecnologia, e trata com absoluta independência as relações com o mercado de capitais e de crédito. Com essa formulação, Jorgenson provou que o coeficiente da variável vendas é dominante e estatisticamente relevante para explicar o comportamento do investimento. As expectativas de vendas das firmas têm, portanto, um importante impacto sobre o gasto de investimento. Em termos econométricos, essa variável predomina sobre outras que possam vir a ser incluídas na equação ${ }^{5}$. De acordo com a citação acima, a ideia de que as expectativas

\footnotetext{
${ }^{4} \mathrm{O}$ estudo de Jorgenson (1971) compara vários estudos sobre o investimento tanto para firmas quanto para grupos de firmas. Além de fazer esta distinção, o autor acuradamente discute os determinantes do estoque de capital em cada abordagem e suas respectivas especificações.

${ }^{5}$ Segundo os critérios elaborados por Jorgenson e Siebert (1968), apenas o modelo neoclássico mantinha consistência interna quando comparado com abordagens concorrentes.
} 
de vendas determinam a trajetória do investimento é subjacente ao modelo do acelerador original comentado por Chirinko (1993).

As versões derivadas,

have been used in empirical investment studies for decades with excellent results. ...strong accelerator effects have clouded the empirical evaluation of the neoclassical model because many versions of the neoclassical approach allow the cost of capital to affect investment only through variables that also include sales output. Therefore, one often cannot determine the separate impact of sales and the cost of capital from this research, and it is difficult to evaluate the independent importance of these channels for policy analysis. (Fazzari, 1993, p. 18)

Na expectativa de um volume de vendas maior, a firma ajusta seu estoque de capital sempre que a taxa de retorno do investimento seja, no mínimo, igual ao custo de capital, representado pela taxa de juros. Os fundamentos dessa teoria têm recebido profundas críticas, principalmente quanto à noção de concorrência perfeita e da produção previamente definida. Existe ainda a condição de estabilidade das expectativas dos preços relativos, da produção e da taxa de juros, revelando uma crença de comportamento do agente econômico um tanto incompatível com a decisão de investimento, a qual requer um exame minucioso e introspectivo do mesmo em relação ao futuro.

A conclusão geral de Fazzari, Hubbard e Peterson (1988) foi a de que os fundos internos, quando testados como determinantes do estoque de capital desejado, representavam de fato o nível do produto. Ainda, quando o produto e o fluxo de caixa eram incluídos como possíveis variáveis explicativas do estoque de capital, somente o produto predominava ${ }^{6}$.

O trabalho seminal de Fazzari, Hubbard e Petersen (1988), seguido pelos de Hoshi, Kashyap e Scharfstein (1991), Fazzari e Petersen (1993), Schaller (1993), e Hubbard, Kashyap e Whited (1995), examinaram o papel das restrições financeiras e o comportamento do investimento a partir de dados em painel divididos em amostras.

$\mathrm{O}$ diferencial na investigação desses últimos autores em relação à abordagem neoclássica foi a decisão de romper com o conceito de firma representativa, o que implicou na separação das firmas em amostras diferentes a partir de critérios a priori que, por hipótese, reuniam firmas que estariam enfrentando restrições de liquidez nos mercados financeiros e firmas que não estariam. Os critérios para separação de firmas nos Estados Unidos eram quantitativos e estavam em sintonia com as características de financiamento baseado no mercado de capitais. Por essa razão Fazzari, Hubbard e Petersen (1988) escolheram o grau de distribuição de dividendos para

${ }^{6}$ Elliot (1973) contesta os resultados econométricos neoclássicos. 
classificar as firmas em restritas e não restritas, identificadas como aquelas que apresentaram uma alta sensibilidade do cash flow ao investimento ${ }^{7}$.

Kaplan e Zingales (1997), KZ de agora em diante, abriram um novo debate ${ }^{8}$ com amplos desdobramentos, em particular feitos por Cleary (1999), Butzen e Fuss (2003) e Hovakimian e Titman (2006).

KZ (1997) questionaram a premissa de Fazzari, Hubbard e Petersen (1988), de que uma maior sensibilidade do investimento às variáveis financeiras internas significaria uma restrição financeira. Uma firma é considerada financeiramente restrita se o custo ou a disponibilidade dos fundos externos impede a companhia de investir o montante que a mesma faria se tivesse fundos internos disponíveis ${ }^{9}$, representado pelo cash flow. KZ (1997) investigaram a amostra de 49 firmas mais restritas segundo o artigo de Fazzari, Hubbard e Petersen (1988), com alta sensibilidade do investimento ao cash flow, e não encontraram mais do que $15 \%$ dessas firmas com dificuldades para obter financiamento nos mercados. Concluíram que as firmas com excesso de cash flow não enfrentavam necessariamente restrição de crédito, entendimento obtido através das leituras dos relatórios das corporações.

KZ (1997) propõem uma análise que combinaria os estudos do perfil financeiro com a análise dos relatórios das empresas publicados, o que estabelece o material básico para obter a leitura exata para saber se uma firma seria ou não restrita em relação à possibilidade de obtenção de fundos no mercado. A relação não monotônica entre investimento e cash flow abriu um amplo campo de investigação.

Cleary (1999) discute os resultados de KZ (1997) e estabelece uma classificação a partir de índices de falências. O autor consegue dar suporte aos resultados de KZ (1997) com uma metodologia que prescinde da leitura de relatórios, usando a análise multivariada dos indicadores para gerar um indicador de insolvência que determine a condição financeira da empresa ao longo do período analisado. As empresas com melhor qualidade financeira demonstraram ser mais sensíveis aos recursos acumulados, cash flow, do que as firmas com padrão financeiro inferior.

Butzen e Fuss (2003) organizaram diversos estudos aplicados a dados de empresas belgas, os quais exploraram modelos com equações de Euler, vetores autorregressivos e forma reduzida. Com essas metodologias, hipóteses relativas às imperfeições

\footnotetext{
${ }^{7}$ Firmas que retinham dividendos registraram uma elevada sensibilidade do cash flow ao investimento, o que para os autores era a prova contundente de que essas sofriam os efeitos das restrições.

${ }^{8}$ Com a noção das assimetrias, desenvolvida nos anos 1970, muitas discussões se ramificaram procurando demonstrar que "finance matters". Modelos baseados em custo de agência, em informações assimétricas, pecking order, modelos de controles e que incluem custos de transações são os principais exemplos.

${ }^{9}$ As conclusões vieram do estudo da amostra de 49 empresas utilizadas por Fazzari, Hubbard e Petersen (1988).
} 
e aos custos de transação foram testadas. Em um desses estudos feito por Gerard e Vershueren (2003, p. 61) os autores concluíram que

All those imperfections result in a possible, sometimes firm-specific, hierarchy among the sources of funds, which can in turn explain why investment expenditures may be limited by the capacity to use internal finance. Such a view provides theoretical support for the frequently observed, and often significant, relation between real investment expenditures and financial variables such as profit and cash flow.

Bruinshoofd (2003) discute a repercussão do trabalho de Fazzari, Hubbard e Petersen (1988) em face do conjunto de trabalhos que se desenvolveram ao longo da década de 1990 nos EUA e em outros países. Somente nos EUA, 16 estudos se seguiram ao de Fazzari, Hubbard e Petersen (1988), investigando novos critérios de seleção, modelos econométricos alternativos e diferentes amostras. Da mesma forma, o autor apresenta outros 22 estudos para o resto do mundo, em países tais como Canadá, Alemanha, Itália e até Equador. De maneira bastante significativa, esse conjunto de estudos tende a comprovar uma maior sensibilidade do investimento às variáveis financeiras, entre elas o cash flow, para as firmas teoricamente mais expostas às imperfeições do mercado.

Contudo, como o próprio Bruinshoofd (2003) enfatiza, esse foi um período no qual muitos dos problemas inerentes ao método de pesquisa tiveram de ser enfrentados, às vezes com respostas não tão conclusivas quanto se esperava. Hubbard (1998) também destacou a importância dessas dificuldades. De acordo com o autor, as principais dificuldades estavam relacionadas com a classificação "a priori” das firmas, a consistência do " $q$ " de Tobin como representante das oportunidades do investimento e a independência entre as variações na liquidez da firma e nas oportunidades de investimento.

Hovakimian e Titman (2006) examinaram a relação entre os recursos obtidos pelas empresas de capital aberto nos Estados Unidos, no período de 1997 a 2000, originados das vendas de ativos e o gasto de investimento em novos ativos. Essa fonte se demonstrou importante nos testes econométricos. Os autores combinaram a noção do financial slack a partir da relação lucros/total de encargos financeiros. Observaram os autores que, durante o período, essa relação e a evidência de venda de ativos fixos foram importantes para dar suporte ao cash flow na determinação do novo investimento. O pressuposto é de que a venda de ativos fixos pode indicar uma situação financeiramente difícil. Os resultados mostraram que a redução dos ativos fixos, por meio das vendas de imobilizado, era importante para financiar as novas aquisições de ativos fixos para as firmas, com o total de lucros antes do juro, imposto e amortização menor que $80 \%$ das despesas com encargos financeiros. 
Com essa metodologia, Hovakimian e Titman (2006) assimilaram as críticas de Kaplan e Zingales $(1997,2000)$ e procuraram evitar critérios quantitativos a priori para classificar as firmas segundo o grau de restrição. Em termos metodológicos, basearam-se nas evidências econômicas (venda de ativos) e financeiras (relação das despesas financeiras e lucros) para testar a hipótese de que os recursos financeiros internos, cash flow, são predominantes no financiamento.

A volumosa produção na literatura baseada na assimetria de informações na teoria do investimento deve-se ao esforço de mostrar que a restrição financeira é uma função linear da sensibilidade do investimento ao cash flow.

Quanto ao problema relacionado à classificação a priori, destacamos que, embora seja bastante conveniente supor que um grupo de firmas se defronte com possibilidades mais adversas de financiamento externo do que outro grupo de firmas, é muito mais plausível considerar que essas condições variam de acordo com as oportunidades de investimento, com a disponibilidade de recursos no mercado, com o estágio de desenvolvimento da firma e dos mercados financeiros e com a própria política de financiamento da empresa. Esses são aspectos problemáticos para os estudos empíricos realizados. Além do mais, em condições de elevada incerteza, as firmas podem revelar um comportamento de precaução, acumulando, assim, reservas para investir em um ponto do tempo. Dessa forma, a relação monotônica entre investimento e cash flow estaria desfeita.

Outra perspectiva sobre a relação positiva entre os fundos gerados internamente pelas firmas - free cash flow hypothesis de Jensen e Meckling (1976) - e o investimento foi formulada a partir do conflito entre os interesses do comitê executivo das firmas (Board of Directors) e dos acionistas. O crescimento da firma, independentemente do valor gerado pelos investimentos, é o foco do comitê que se beneficia do crescimento em função do grau de intervenção e de poder que passa a deter. Uma questão difícil de ser identificada é o uso do free cash flow com relação às estratégias das firmas em regime de competição oligopolista, na qual a estratégia de participação no mercado se mistura com a decisão de participação em segmentos correlacionados. Na perspectiva da estratégia, o crescimento pode ser o prioritário, explicando o excesso de investimento.

Quanto à incerteza dos projetos de investimento, a questão da irreversibilidade das decisões e a importância da liquidez elevada, enquanto forma de se precaver, foram exploradas antes do debate levantado por KZ. Abel (1983), Abel e Eberly (1999), Caballero (1991), Dixity e Pindyck (1994) são alguns exemplos. Os argumentos contidos nesses estudos na essência predizem que uma firma sob incerteza quanto aos resultados do projeto de investimento a ser implantado e com alguma flexibilidade temporal pode adiar o investimento para aguardar informações adicionais. A comparação entre 
os custos de adiamento em regime de competição oligopolista e os ganhos do adiamento é que determinará o valor da opção de aguardar.

A demanda das empresas por liquidez baseia-se na perspectiva de que o acúmulo de recursos na forma quase líquida aumenta as chances de aproveitamento das oportunidades de investimento em títulos, participações em empresas e aquisição de ativos fixos.

No processo de aquisição de informação adicional, há um efeito preventivo que leva as firmas a acumularem recursos líquidos. As firmas acumulam recursos para evitar que flutuações econômicas e incertezas dos projetos de investimento afetem negativamente a capacidade de saldar as dívidas no curto prazo.

A acumulação de cash flow e o ajustamento do estoque de capital passam a depender de estratégias empresariais nas quais alguma medida de possível insucesso causaria interferência na lógica de aquisição de capital fixo. O resultado prático é a quebra da relação monotônica entre cash flow e investimento.

Dessa discussão criaram-se duas especializações nos estudos sobre os determinantes do investimento. A primeira trata de identificar com precisão as evidências de restrições de liquidez e a segunda procura encontrar a melhor estruturação do modelo econométrico para identificar a sensibilidade do investimento ao cash flow.

Ao empregar complementos entre metodologias (análise de indicadores econômico-financeiros e método econométrico) buscamos avançar nas duas especializações que citamos acima registrada pela literatura. A primeira especialização visa superar a limitação em separar firmas em amostras levantada por Kaplan e Zingales (1997, 2000). Superamos essa limitação evitando critérios quantitativos relativos ao desempenho financeiro das firmas. Por isso, partimos do índice de negociabilidade da Bolsa de Valores, que é uma medida externa, ou seja, uma medida do mercado quanto à qualidade econômico-financeira das empresas. A segunda especialização visa superar a limitação de caracterização das condições de restrição financeira baseadas exclusivamente nas circunstâncias internas das firmas, com fez Cleary (1999), ou que denunciem adversidades financeiras graves, como feito por Hovakimian e Titman (2006). Superamos essa limitação propondo observar o comportamento das firmas sob uma condição de instabilidade macroeconômica, como a que ocorreu no Brasil de 1998 a 2000.

Se a qualidade das informações das firmas dá o suporte ao índice de negociabilidade é de se esperar que as empresas participantes desse índice não encontrem problemas para obter financiamento nos mercados financeiros.

Essas duas frentes são complementares e, com relação à primeira, trataremos de analisar as informações através de índices econômico-financeiros. Quanto à segunda, o debate teórico nos levou a certos ajustes inevitáveis ao modelo referencial, segundo o background analisado por Chirinko (1993). Ao introduzirmos o capital circulante 
líquido ${ }^{10}$ na equação a ser estimada, a exemplo de Fazzari e Petersen (1993), conseguimos analisar as restrições de liquidez de forma direta, pois o capital circulante líquido indica a condição de liquidez geral das firmas, antes mesmo do cash flow.

O cash flow não é o foco da condição de liquidez mais geral e, portanto, não é a variável isolada a ser observada com relação à sensibilidade do investimento, mas sim o comportamento do capital circulante líquido e o investimento em ativos fixos.

Essa modificação torna-se mais importante quando há evidências de restrições de crédito em uma economia independente de sua causa. Além de acumular lucros, as firmas podem manusear variáveis do lado do passivo ou do ativo para alterar o capital circulante líquido, classicamente a variável que representa o grau de liquidez das firmas. Com isso uma firma poderá complementar as necessidades de desembolsos relativas ao gasto de investimento, além dos lucros e do financiamento de longo prazo que possam conseguir.

O capital circulante se comporta de forma pró-cíclica. Nas recessões ou choques, esse capital é reduzido. Nas fases de expansão, tende a aumentar, muito embora logo no início da fase de expansão haja um grande consumo de recursos líquidos envolvidos nas atividades produtivas. Assim, após ter seu volume reduzido, o capital circulante começa a crescer em função da expansão das atividades econômicas. Podemos caracterizá-lo nessa fase de crescimento como uma variável pró-cíclica e lag.

O modelo de investimento fornece o sinal e os parâmetros dos determinantes do dispêndio em capital fixo. Se o sinal do parâmetro do capital circulante for positivo, indicará que está ocorrendo investimento no capital circulante, o que aumenta a liquidez; se for negativo, indicará que o capital circulante está sendo contraído para criar a liquidez necessária para financiar outros dispêndios.

A questão fundamental para os estudos empíricos é conseguir, portanto, isolar as relações entre a estrutura de capital das empresas e o gasto de investimento. A análise de indicadores econômico-financeiros fornecerá a evidência do grau de interdependência entre as decisões de investir e financiar a partir da estrutura de capital e do dispêndio de investimento. Com isso, buscamos oferecer uma perspectiva das relações entre as variáveis financeiras para subsidiar os resultados alcançados com o modelo econométrico. $\mathrm{O}$ modelo econométrico e os resultados gerados serão apresentados na seção 4 .

\footnotetext{
${ }^{10} \mathrm{O}$ capital circulante líquido é calculado a partir dos dados da demonstração contábil denominada de balanço patrimonial. Do lado esquerdo do balanço, estão os ativos circulantes (moeda e direitos de curto prazo), e do direito, o passivo circulante (obrigações de curto prazo). A diferença entre ativo circulante e passivo circulante é o capital circulante líquido, que representa a liquidez de uma firma.
} 


\section{INDICADORES, COMPORTAMENTO AMOSTRAL E EVIDÊNCIAS}

A composição da amostra para a investigação foi feita através do critério de negociabilidade das ações no ano 1998. Não se encontram alterações substantivas nas posições das empresas com as ações mais negociadas de 1995 a 2000.

As 334 empresas mais negociadas oferecem maior liquidez e rentabilidade aos investidores. $\mathrm{Na}$ leitura do mercado, são empresas consistentes diante da transparência de suas informações. São empresas que deveriam encontrar recursos dos mercados financeiros em qualquer situação, dada a transparência de suas informações reveladas ao mercado conforme as normas de governança. Por serem as empresas mais negociadas na bolsa de valores, as 334 empresas da amostra ofereceram liquidez acionária e rentabilidade aos acionistas.

A leitura dos resultados dos indicadores econômico-financeiros permitirá avaliar como a leitura econométrica é amparada ou amplificada pela explanação dos indicadores.

A metodologia de indicadores financeiros e a interpretação do modelo econométrico se completam. Na dimensão dos indicadores identificam-se as decisões de investir em ativos fixos e/ou líquidos. $\mathrm{Na}$ dimensão do modelo econométrico, encontram-se os determinantes do investimento. Os indicadores, por outro lado, são plurais. Mostram toda a estratégia empresarial. O modelo econométrico é específico e revela os sinais de parâmetros que explicam o gasto de investimento.

Os indicadores selecionados compreendem a liquidez, endividamento, grau de imobilização de recursos, cash flow, investimento, retorno do ativo, grau de alavancagem e capital circulante. Todas as variáveis foram ponderadas pelo estoque de capital da firma.

O balanço patrimonial possui dois lados. O lado esquerdo representa os investimentos em ativos que se dividem, por sua vez, em curto e longo prazos. $\mathrm{O}$ ativo circulante é de curto prazo e relaciona-se diretamente com a atividade produtiva da empresa. $\mathrm{O}$ ativo não circulante é subdividido em investimentos, que compreendem a participação em empresas coligadas, e imobilizado, que representa o conjunto de bens que forma o estoque de capital fixo da empresa. O lado direito é do passivo total e do patrimônio líquido, que compreendem o financiamento total, oriundo de capitais de terceiros (soma do passivo circulante com o não circulante) e de capital próprio, representado pelo patrimônio líquido.

O segundo conjunto de variáveis, que levam aos cálculos dos indicadores, é a demonstração de resultados, que tem por finalidade informar o resultado (lucros ou prejuízo) do período. A demonstração de resultado é construída de forma dedutiva, ou seja, a partir da receita líquida de vendas (após a dedução dos impostos indiretos) deduzindo-se os custos diretos de produção e as despesas fixas, mais juros e impostos diretos, gerando, assim, o resultado, lucro ou prejuízo. 
Os ativos devem gerar um rendimento suficiente para saldar os custos e as despesas operacionais e financeiras, e proporcionar lucros. Os lucros aumentam a liquidez (capital circulante líquido) e levam à redução do nível de endividamento de uma empresa.

A liquidez (capital circulante líquido) pode ser alterada também pelos empréstimos de longo prazo. Uma vez que esses empréstimos têm como contrapartida o caixa da empresa, o ativo circulante líquido é acrescido de uma soma adicional de recursos em relação ao passivo circulante.

Para entender os comportamentos financeiro e econômico da amostra no período, inicia-se a próxima seção com os indicadores de liquidez e de participação de terceiros e a composição do endividamento.

\subsection{ANÁLISE FINANCEIRA E ECONÔMICA DA AMOSTRA}

A capacidade de saldar dívidas é denominada liquidez corrente. A existência de 1,65 unidades monetárias a receber para cada unidade de dívida, segundo a média do período, é uma característica há alguns anos das empresas de capital aberto, inclusive antes do período analisado. $\mathrm{O}$ aspecto frágil é a participação de terceiros, $61 \%$ do financiamento total, combinada com a composição de $58 \%$ de curto prazo, segundo a média do período. O capital próprio (patrimônio líquido) atingiu $39 \%$ do financiamento total. O predomínio do financiamento de curto prazo de terceiros é o aspecto preocupante quando ocorrem flutuações adversas de demanda. Os ajustamentos, neste caso, são realizados através da redução de gastos e quantidades, tanto de produtos em processo quanto de emprego.

Tabela 1 - Liquidez e participação de terceiros

\begin{tabular}{l|c|c|c|c|c|c}
\hline \multirow{2}{*}{ Ano/Medidas } & \multicolumn{2}{|c|}{ Liquidez Corrente* } & \multicolumn{2}{c}{ Participação de Terceiros** } & \multicolumn{2}{c}{$\begin{array}{c}\text { Composição do } \\
\text { Endividamento } \\
\text { (curto prazo) }\end{array}$} \\
\cline { 2 - 7 } & Média & Mediana & Média & Mediana & Média & Mediana \\
\hline 1995 & 1,56 & 1,07 & 0,42 & 0,35 & 0,61 & 0,64 \\
\hline 1996 & 1,57 & 1,13 & 0,53 & 0,39 & 0,59 & 0,61 \\
\hline 1997 & 1,64 & 1,10 & 0,57 & 0,41 & 0,57 & 0,58 \\
\hline 1998 & 1,54 & 1,12 & 0,68 & 0,44 & 0,58 & 0,57 \\
\hline 1999 & 2,0 & 1,0 & 0,74 & 0,50 & 0,57 & 0,55 \\
\hline 2000 & 1,59 & 1,12 & 0,72 & 0,50 & 0,54 & 0,54 \\
\hline Todos os Anos & 1,65 & 1,09 & 0,61 & 0,44 & 0,58 & 0,58 \\
\hline
\end{tabular}

Notas: (*)Liquidez Corrente - ativo circulante/passivo circulante; (**)Participação de Terceiros (passivo circulante + empréstimos de longo prazo), (Participação de Terceiros)/Participação de terceiros + Patrimônio Líquido);

${ }^{(* * *)}$ Composição de Endividamento: (passivo circulante/capitais de terceiros).

Fonte: Elaboração própria com dados de empresas de capital aberto do banco de dados da ECONOMÁTICA. 
Se no plano da liquidez e do endividamento há uma perspectiva de fragilidade em função da menor participação de recursos próprios, representada pelo patrimônio líquido e de terceiros de longo prazo, a imobilização de recursos, na Tabela 2, revela um aspecto da situação econômica com desdobramentos financeiros a considerar.

O grau de imobilização do patrimônio indica o quanto do capital próprio (patrimônio líquido) foi transformado em ativos permanentes que se destinam às operações produtivas. O grau de imobilização médio atingiu 1,54 (Tabela 2) e foi o dobro do patrimônio líquido em 2000. Em termos práticos, isso significa que as empresas imobilizaram recursos em ativos de menor liquidez (ativos imobilizados e participações em coligadas) dentre as opções de aquisições de ativos. O que excedeu a unidade foi financiado com recursos de terceiros de longo prazo.

O grau de imobilização de recursos não correntes (somatório do patrimônio líquido e dos empréstimos de longo prazo) mostrou que 1995 foi um ano crítico, com o ativo permanente consumindo todos os recursos do patrimônio líquido (capital próprio) e de terceiros de longo prazo. Para financiar os ativos circulantes, as empresas recorreram a recursos de terceiros de curto prazo. Nessas condições, a liquidez torna-se a variável crucial na administração financeira, devido ao grande fluxo de recursos destinados à aquisição de ativos fixos.

Tabela 2 - Imobilização de recursos

\begin{tabular}{|c|c|c|c|c|}
\hline \multirow[t]{2}{*}{ Ano/Medidas } & \multicolumn{2}{|c|}{$\begin{array}{l}\text { Grau de Imobilização do } \\
\text { Patrimônio Líquido* }\end{array}$} & \multicolumn{2}{|c|}{$\begin{array}{l}\text { Grau de Imobilização de Recursos não } \\
\text { Correntes }^{* *}\end{array}$} \\
\hline & Média & Mediana & Média & Mediana \\
\hline 1995 & 1,16 & 1,02 & 1,05 & 0,9 \\
\hline 1996 & 1,57 & 1,03 & 0,84 & 0,86 \\
\hline 1997 & 1,58 & 1,04 & 0,85 & 0,83 \\
\hline 1998 & 1,68 & 1,02 & 1,00 & 0,80 \\
\hline 1999 & 1,56 & 1,02 & 0,85 & 0,80 \\
\hline 2000 & 2,12 & 1,04 & 0,82 & 0,79 \\
\hline Todos os Anos & 1,54 & 1,03 & 0,83 & 0,83 \\
\hline
\end{tabular}

Notas: (*)Grau de Imobilização do Patrimônio Líquido: ativo permanente/patrimônio líquido; ${ }^{(* *)}$ Grau de imobilização de recursos não correntes: (ativo permanente/patrimônio líquido + empréstimos de longo prazo).

Fonte: Elaboração própria com dados de empresas de capital aberto do banco de dados da ECONOMÁTICA

Em termos de média do período, os recursos não correntes de $83 \%$ foram absorvidos pelo ativo permanente, restando $17 \%$ para o financiamento das atividades de curto prazo ou giro dos negócios (capital circulante líquido). A gestão financeira de maneira geral deu-se basicamente com recursos de terceiros de curto prazo. Segundo os indicadores de imobilização de recursos, as flutuações econômicas adversas prejudicam com facilidade as condições financeiras das empresas. 
A consequência do elevado grau de imobilização de recursos é a necessidade de liquidez, que foi mantida estável (Tabela 1). A liquidez, por sua vez, depende da margem de lucro e do giro da atividade que sustentam o grau de endividamento e de imobilização de recursos. A flutuação da demanda e a capacidade de pagamento dos consumidores tornam-se relevantes para os planos de continuidade de investimento das empresas.

A Tabela 3 registra o retorno positivo dos ativos (ROA) e do patrimônio líquido (ROE) em todos os anos do período. Se todo financiamento fosse feito com recursos próprios, o retorno do ativo seria necessariamente igual ao retorno do patrimônio. A presença de recursos de terceiros e, consequentemente, de despesas financeiras causa diferenças entre os dois retornos. A presença de capitais de terceiro eleva o valor do balanço patrimonial (do lado do ativo e do passivo igualmente). O lucro é reduzido pelo valor das despesas financeiras. No cálculo do ROA, o valor do ativo aumenta (dada a presença de capitais de terceiros) e o numerador (lucro) diminui em função das despesas financeiras e amortizações. No cálculo do ROE, o numerador (lucro) é o mesmo do cálculo anterior para o ROA; no entanto, o denominador (patrimônio líquido) é menor do que o ativo total. Se a divisão do ROE pelo ROA for maior do que a unidade então há alavancagem.

A alavancagem existe porque o efeito de tomar recursos de terceiros em uma ponta, a determinado custo, aplicando-se em outra ponta (em ativos) a uma taxa de retorno superior ao da captação, proporciona uma diferença entre os retornos apropriada para os acionistas. A diferença pode ser observada a partir da divisão da taxa de retorno dos ativos pela taxa de retorno do patrimônio. Os resultados demonstram que a estrutura de capital das firmas no mercado aberto no Brasil permitiu a geração de alavancagem. Apesar da presença de $58 \%$ de capitais de curto prazo, os custos foram menores do que a taxa de retorno dos ativos.

Na Tabela 3, o retorno dos proprietários é um incentivo à realização de investimentos, observadas as condições de concorrência e as expectativas empresariais. Dada a alavancagem, há incentivos para que as empresas utilizem recursos de terceiros na estrutura de financiamento, como o fizeram, conseguindo assim um retorno do capital próprio acima do retorno dos ativos.

A Tabela 4 apresenta a proporção do cash flow com relação ao estoque de capital e dois tipos de investimentos. O primeiro é em contas circulantes, que pode representar tanto o aumento do ativo circulante quanto a redução do passivo circulante. $\mathrm{O}$ segundo consiste em aquisições e ativos imobilizados. 
Tabela 3 - Retorno dos ativos, do patrimônio e alavancagem financeira

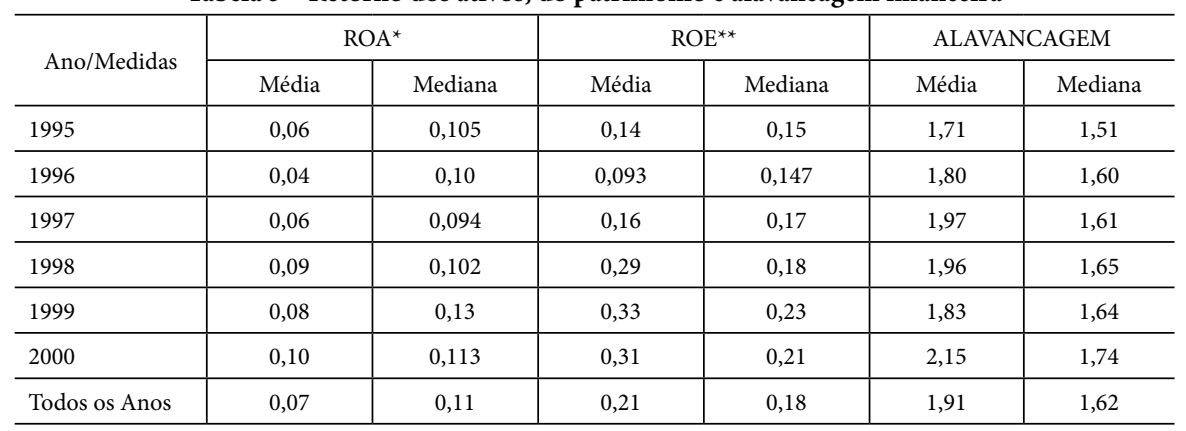

Notas: ${ }^{*}$ ROA - lucro líquido/ativo total; ${ }^{(* *)}$ ROE - lucro líquido/patrimônio líquido.

Fonte: Elaboração própria com dados de empresas de capital aberto do banco de dados da ECONOMÁTICA.

Para encontrar a variação do capital circulante líquido, é necessário, em primeiro lugar, ter os valores do capital circulante líquido (CCL) de cada ano. O CCL, por sua vez, é o resultado da diferença entre o ativo circulante (moeda, aplicações financeiras, títulos a receber e estoques) e o passivo circulante (obrigações de curto prazo). O capital circulante líquido do ano menos o capital circulante líquido do ano $t_{-1}$ resulta na variação do CCL.

Quando a variação é positiva, há aplicações ou investimentos nas contas circulantes, através do aumento do valor do ativo circulante ou da redução de valor do passivo circulante. Quando a variação é negativa, há origem ou criação de liquidez, através da redução do valor do ativo circulante ou do aumento do valor do passivo circulante.

Os investimentos no ativo imobilizado não superaram a média de 16\% (Tabela 4). A soma dos lucros com a depreciação (cash flow) superou os recursos investidos em ativos fixos. Dessa forma, houve condições favoráveis para o autofinanciamento. Além dessa condição, é importante explicitar a presença de outra fonte de financiamento, oriunda da contração do capital circulante líquido.

De acordo com a Tabela 4, o capital circulante líquido, que é um recurso pró-cíclico e que garante a liquidez das firmas, sofreu contração de 1995 a 1999 (exceção em 2000). Nos anos 1998 e 1999, a redução foi bastante significativa e superou a soma dos lucros com a depreciação (cash flow). No ano 2000, ocorreu a aplicação de recursos em capital circulante. 
Tabela 4 - Cash flow, investimento e variação do capital circulante

\begin{tabular}{l|c|c|c|c|c|c}
\hline \multirow{2}{*}{ Ano/Medidas } & \multicolumn{2}{|c|}{ Cash flow $^{*}$} & \multicolumn{2}{c|}{$\begin{array}{c}\text { Variação do Capital } \\
\text { Circulante** }\end{array}$} & \multicolumn{2}{c}{ Investimento $^{* * *}$} \\
\cline { 2 - 7 } & Média & Mediana & Média & Mediana & Média & Mediana \\
\hline 1995 & 0,18 & 0,12 & $-0,02$ & 0,00 & 0,15 & 0,09 \\
\hline 1996 & 0,19 & 0,13 & $-0,03$ & 0,05 & 0,15 & 0,09 \\
\hline 1997 & 0,35 & 0,15 & $-0,04$ & 0,01 & 0,16 & 0,094 \\
\hline 1998 & 0,18 & 0,12 & $-0,23$ & $-0,02$ & 0,16 & 0,10 \\
\hline 1999 & 0,20 & 0,09 & $-0,31$ & $-0,01$ & 0,15 & 0,097 \\
\hline 2000 & 0,56 & 0,17 & 0,17 & 0,04 & 0,12 & 0,095 \\
\hline Todos os Anos & 0,22 & 0,125 & $-0,126$ & 0.005 & 0,148 & 0,10 \\
\hline
\end{tabular}

Notas: ${ }^{(*)}$ Cash flow - (Lucros + depreciação)/estoque de capital; ${ }^{(* *)}$ Variação do Capital Circulante Líquido - (Capital circulante em $t$ - Capital Circulante em $t$-1)/estoque de capital; ${ }^{(* * *)}$ Investimento - (acréscimo do imobilizado)/estoque de capital. Fonte: Elaboração própria com dados de empresas de capital aberto do banco de dados da ECONOMÁTICA.

O comportamento do capital circulante líquido nos três anos selecionados para o estudo (1998, 1999 e 2000) difere dos anos anteriores. O ano 1998 foi tenso com relação às expectativas de mudança cambial e, assim como o de de 1999 em função de crises externas, tal como a ocorrida com a Argentina, e do comportamento de overshooting da taxa de câmbio no Brasil após o fim do regime das bandas cambiais. Após dois anos reduzindo o capital circulante, as empresas voltaram a aplicar recursos nas contas circulantes no ano 2000, quando a aplicação em investimento imobilizado foi a menor do período.

Em termos teóricos, a decisão de investir em ativos circulantes concorre com a decisão de investimento em ativos imobilizados quando há restrição de recursos. É esperado, portanto, que o sinal do parâmetro do capital circulante líquido na equação econométrica seja negativo, indicando a necessidade de recursos de curto prazo para completar o volume de recursos para a aquisição de ativos fixos.

Dentro do modelo de investimento, o parâmetro da variação do capital circulante líquido para o conjunto das empresas pode ter sinal negativo ou positivo. Se negativo, significará que os investimentos em ativo imobilizado superaram as fontes de financiamento de longo prazo e, portanto, recursos do capital circulante foram necessários para complementar o financiamento total. Se o parâmetro for positivo, significará que os recursos de longo prazo, mais lucro e depreciação, excederam o volume de investimentos. Dessa forma, sobraram recursos, que foram destinados ou à aquisição de ativos circulantes (curto prazo) ou à redução de passivos circulantes.

Em termos financeiros, segundo a Tabela 4, houve a contração de recursos circulantes, com exceção do ano 2000. O volume de recursos oriundos da redução do capital circulante pode ter sido usado para financiar os investimentos em ativos imobilizados em conjunto com o cash flow e com financiamento de longo prazo. É 
isso que procuraremos observar no modelo econométrico, ou seja, a importância do cash flow, da variação do capital circulante, das vendas e dos recursos de longo prazo na equação econométrica.

\section{MODELO E REFLEXÕES SOBRE RESULTADOS ECONOMÉTRICOS}

O instrumental econométrico utilizado é o método dos mínimos quadrados nos dois estágios. Mediante a simultaneidade das decisões de investir em ativos fixos e contrair ou expandir o capital circulante líquido, é necessário utilizar um grupo de variáveis instrumentais que serão depois, em um segundo estágio, utilizadas dentro da equação de estimação.

As variáveis endógenas ao modelo são: o investimento em ativo fixo e o investimento em capital circulante líquido. Quanto a este último, o sinal do parâmetro indicará no teste econométrico se as firmas estão aumentando o capital circulante (sinal positivo) ou reduzindo esse capital (sinal negativo) para, nesse caso, produzir a liquidez necessária. As variáveis instrumentais são: vendas e capital circulante líquido no início do período. Esses instrumentos se relacionam com os lucros e a variação do capital circulante, que são, como afirmamos, nossas variáveis endógenas neste modelo.

A variação positiva de capital circulante líquido constitui um investimento em ativos líquidos e a contração significa a criação de financiamento a partir de recursos correntes ou de curto prazo. A linha de equação estimada é dada abaixo:

$$
\frac{I}{k_{t-1}}=\beta_{1}+\beta_{2} \frac{s}{k_{t-1}}+\beta_{3} \frac{s_{t-1}}{k_{t-1}}+\beta_{4} \frac{c f}{k_{t-1}}+\beta_{5} \frac{c f_{t-1}}{k_{t-1}}+\beta_{6} \frac{f i n}{k_{t-1}}+\beta_{7} \frac{v c g}{k_{t-1}}+\varepsilon_{t}
$$

As variáveis da equação (3) são:

$I=$ investimentos;

$K_{t}=$ estoque de capital do período;

$K_{t-1}=$ estoque de capital defasado;

$S=$ vendas;

$S_{t-1}=$ vendas defasadas em um período;

$c f=$ cash flow;

$c f_{t-1}=$ cash flow defasado em um período;

fin = empréstimos de longo prazo;

$v c g=$ variação do capital circulante líquido.

As variáveis do modelo foram ponderadas pelo estoque de capital no início do período, $K_{t-1}$, com o objetivo de reduzir as diferenças de tamanho entre as empresas, controlando a heterocedasticidade. 
As variáveis acima foram coletadas das demonstrações contábeis disponibilizadas pela Comissão de Valores Mobiliários (CVM). Depois de coletadas, foram agregadas por firma e por ano. Com isso, construímos o conjunto de dados com observações de cada firma para cada respectivo ano. As variáveis que não contêm informações são descartadas, de tal modo que temos um painel desequilibrado com um total de 138 empresas ${ }^{11}$, com informações que vão de 1995 a $2000^{12}$, mas não para todo o período em grande parte dos casos, totalizando 709 observações.

Na Tabela 5, temos os resultados da estimação do modelo por três métodos diferentes: por mínimos quadrados ordinários (modelo 1), por efeitos fixos (modelo 2) e, finalmente, um modelo dinâmico estimado pelo método generalizado dos momentos (GMM). Em todos os modelos, foram incluídos os efeitos temporais, isto é, as variáveis dummy para os anos de 1997 a 2000 . Não é possível incluir uma variável dummy para o ano 1996 em função das defasagens de variáveis do modelo e, no modelo dinâmico, a variável dummy para o ano 1997 também teve de ser excluída, tendo em vista a necessária instrumentalização para a estimação por GMM.

Como esperado, há importantes diferenças, tanto de sinais como de significância dos três modelos. Os resultados do modelo (2) indicam que os efeitos fixos (que nada mais são, nesse caso, que os "efeitos-firma") são relevantes, apesar de não serem mostrados na tabela. A partir dos resultados do modelo (2), é possível perceber onde há a mudança de sinal da variável de fluxo de caixa, tanto a presente quanto a defasada, embora em ambos os casos a estimativa fosse significante a $1 \%$, indicando a existência de viés nas estimativas do modelo (1).

O outro passo foi estimar o modelo (3), com a inclusão da variável dependente (investimento) defasada, o que torna o modelo dinâmico e daí, a necessidade de estimá-lo pelo método generalizado dos momentos, sem o qual as estimativas seriam inconsistentes. Esse passo mostrou a relevância dessa estimação e isso pode ser constatado diretamente pela observação da significância (a 1\%) da variável dependente defasada.

\footnotetext{
${ }^{11}$ Há que se notar que, das 334 empresas utilizadas a princípio, nem todas tinham informações de todas as variáveis explicativas do modelo, daí a necessidade de redução na amostra utilizada.

${ }^{12}$ Há a necessidade de expandir a amostra no passado, isto é, antes de 1998, que é o objetivo do trabalho, tendo em vista a presença de variáveis defasadas no modelo e a posterior estimação do modelo dinâmico, que necessita também de variáveis defasadas que serão utilizadas como instrumentos, visando uma estimação consistente.
} 
Tabela 5 - Resultados das estimações (variável dependente: $I / K_{t-1}$ )

\begin{tabular}{|c|c|c|c|}
\hline Variável & Modelo (1) & Modelo (2) & Modelo (3) \\
\hline Constante & $\begin{array}{c}-0,20966 \\
(1,694) \\
\end{array}$ & $\begin{array}{c}-0,42972 \\
(6,5073) \\
\end{array}$ & $\begin{array}{l}0,68266 \\
(2,8164) \\
\end{array}$ \\
\hline Investimento em $t-1 \quad(I)$ & & & $\begin{array}{c}1,8046^{* * *} \\
(0,27076)\end{array}$ \\
\hline Vendas $(S)$ & $\begin{array}{c}-0,071872^{* * *} \\
(0,0086774)\end{array}$ & $\begin{array}{c}-0,091571^{* * *} \\
(0,0085225)\end{array}$ & $\begin{array}{c}-0,12517^{* * *} \\
(0,0053252)\end{array}$ \\
\hline Vendas em $t-1(S)$ & $\begin{array}{l}0,10464^{* * *} \\
(0,0087513)\end{array}$ & $\begin{array}{l}0,13234^{* * *} \\
(0,0087479)\end{array}$ & $\begin{array}{l}0,1083^{* * *} \\
(0,0090749)\end{array}$ \\
\hline Financiamento ( $f$ in) & $\begin{array}{l}-0,01266 \\
(0,014659) \\
\end{array}$ & $\begin{array}{c}-0,028379^{* *} \\
(0,014098) \\
\end{array}$ & $\begin{array}{c}-0,038024^{* * *} \\
(0,0058287) \\
\end{array}$ \\
\hline Fluxo de caixa ( $c f)$ & $\begin{array}{c}0,033721^{* * *} \\
(0,0026785)\end{array}$ & $\begin{array}{c}-0,0032006 \\
(0,0050823)\end{array}$ & $\begin{array}{c}-0,098535^{\star *} \\
(0,49202)\end{array}$ \\
\hline Fluxo de caixa em $t-1(c f)$ & $\begin{array}{c}0,030558^{* * *} \\
(0,0032329) \\
\end{array}$ & $\begin{array}{c}-0,015579^{* * *} \\
(0,0061741) \\
\end{array}$ & $\begin{array}{c}0,20915^{* * *} \\
(0,021003) \\
\end{array}$ \\
\hline Var.c.circulante $(v c g)$ & $\begin{array}{c}-0,25892^{\star * *} \\
(0,0082657) \\
\end{array}$ & $\begin{array}{c}-0,30377^{\star * *} \\
(0,0086765)\end{array}$ & $\begin{array}{c}-0,33977^{\star * *} \\
(0,0050004)\end{array}$ \\
\hline D2000 & $\begin{array}{c}-0,83511 \\
(2,3321) \\
\end{array}$ & $\begin{array}{r}0,39007 \\
(2,0983) \\
\end{array}$ & $\begin{array}{l}0,12148 \\
(0,84074) \\
\end{array}$ \\
\hline D1999 & $\begin{array}{l}2,0423 \\
(2,2663) \\
\end{array}$ & $\begin{array}{l}3,0832 \\
(2,0214) \\
\end{array}$ & $\begin{array}{l}0,32467 \\
(0,83895) \\
\end{array}$ \\
\hline D1998 & $\begin{array}{c}1,035 \\
(2,3018) \\
\end{array}$ & $\begin{array}{l}0,16035 \\
(2,0287) \\
\end{array}$ & $\begin{array}{c}-0,018471 \\
(0,81629) \\
\end{array}$ \\
\hline D1997 & $\begin{array}{l}-1,5777 \\
(2,2729)\end{array}$ & $\begin{array}{c}0,0060662 \\
(1,9818)\end{array}$ & \\
\hline
\end{tabular}

Notas: Erros padrão entre parênteses. Modelo (1): mínimos quadrados ordinários justapostos (pooled OLS). Modelo (2): estimação por efeitos fixos. Modelo (3): painel dinâmico com efeitos fixos (estimação por GMM). (*) Significante a 10\%; ${ }^{(* *)}$ Significante a $5 \%$; ${ }^{(* * *)}$ Significante a $1 \%$.

Fonte: Elaboração própria com dados de empresas de capital aberto do banco de dados da ECONOMÁTICA

Se observarmos os demais resultados do modelo dinâmico, percebemos que, mesmo com a inclusão da defasagem da variável dependente, todas as variáveis defasadas previstas pelo modelo teórico continuam significantes, com uma importante mudança de sinal para o fluxo de caixa defasado, indicando que as estimações anteriores padeciam de viés de omissão de variáveis. Dessa forma, o resultado obtido pelo modelo (3) pode ser considerado o "definitivo".

Os efeitos temporais não se mostraram significantes. O efeito do ano de 1999, justamente o ano da desvalorização cambial, foi o único que apresentou uma estatística $t$ superior a 1 , mas isto apenas no modelo (2); tal resultado não foi mantido no modelo (3).

Os resultados das vendas no período $\left(S_{t}\right)$ e no período anterior $\left(S_{t-1}\right)$ mostram que as empresas têm incentivos para investir quando as vendas passadas expandem-se. No entanto, quando ocorre crescimento de vendas no período, o efeito sobre o investimento é negativo, sugerindo que as empresas atendem a demanda deslocando os recursos disponíveis para a produção. Quanto ao fluxo de caixa, o parâmetro do ano anterior é positivo, o que é coerente com a expansão das vendas também do período 
anterior. Ao expandir o mercado em $t_{-1}$, as empresas expandem o valor das vendas e o próprio fluxo de caixa em $t_{-1}$.

No período corrente, $t$, a expansão de vendas absorve recursos líquidos devido à necessidade de aquisições de estoques, financiamento de clientes e aumento de custos variáveis. O fluxo de caixa é usado para o financiamento da produção. Os sinais contrários do fluxo de caixa em $t_{-1}$ e $t$ indicam que essa variável não está funcionando como proxy de rentabilidade futura. O financiamento de longo prazo ( $f i n$ ), pelo que sugere o sinal negativo obtido para essa variável, não foi usado para financiar os ativos fixos em média, mas para reestruturar as dívidas das empresas em face da mudança cambial e das necessidades de capital de giro.

O sinal negativo do capital de giro $(v c g)$ reforça a análise financeira de que o fluxo de curto prazo é importante para a aquisição de ativos fixos. Como o capital de giro é um recurso administrado diretamente pela empresa, sua variação depende dos planos estratégicos não observados pelas gerências. Similarmente, o investimento em ativos fixos é conduzido também pela gerência. Segundo os resultados da Tabela 5, o aumento dos ativos fixos dependeu da redução do capital circulante líquido.

O sinal negativo dos parâmetros do fluxo de caixa e da variação do capital circulante líquido no período $t$ requer uma explicação adicional. As empresas em média obtiveram lucros (Tabela 3 - retorno sobre os ativos ROA). Tal resultado implicaria na variação positiva do capital circulante líquido. Na equação do investimento (Tabela 5), os lucros não afetaram o sinal da variação do capital de giro ( $v c g$ ) que continuou negativo. Logo, o cash flow não é proxy para a rentabilidade futura, mas fonte de recursos de curto prazo utilizada para financiar os gastos de investimento.

\section{OBSERVAÇÕES FINAIS}

O presente estudo demonstrou que o financiamento das empresas de capital aberto no Brasil dependeu da liquidez proporcionada pela redução do capital circulante líquido, pela defasagem das variáveis cash flow e pelas vendas. A soma dos lucros e da depreciação do período, e o sinal negativo do capital circulante líquido demonstram que a variável cash flow não está funcionando como proxy de lucratividade no modelo. Os financiamentos de longo prazo tiveram outra função, além da função de financiar as aquisições de investimento que, por sua vez, dependeram da liquidez acumulada internamente pelas firmas.

A administração do capital circulante (sua contração ou aumento) possibilitou uma leitura das expectativas que se alteraram em relação aos anos 1998, 1999 e 2000. As empresas passaram a se preocupar com a manutenção da liquidez, que cresceu somente no ano 1999 (Tabela 1), porém só não cresceu mais porque as empresas reduziram 
as dívidas de curto prazo, como mostra a composição do endividamento na mesma Tabela 1. Além disso, as firmas financiaram as aquisições de investimento produtivo, como confirmou o parâmetro do capital circulante líquido na Tabela 5.

Na última seção, estimamos um modelo para explicar quais as fontes do financiamento das empresas. A amostra inicialmente com 334 empresas teve que ser reduzida para 138 em função da ausência de algumas informações referentes às variáveis do modelo para um número considerável de empresas. A amostra restante, entretanto, ainda pode ser considerada muito boa para estimar o modelo pretendido. Os dados utilizados foram de 1995 a 2000 - uma expansão necessária do período a que se propõe o trabalho, tendo em vista as defasagens previstas no modelo teórico e uma eventual estimação de um modelo dinâmico. Como para muitas empresas não dispomos de informações de todo esse período, trata-se de um painel desequilibrado.

Além das variáveis previstas pelo modelo teórico, foram incluídos: efeitos temporais em todas as estimações; efeitos fixos (efeitos-firma) nos modelos (2) e (3), cujos coeficientes não foram mostrados na tabela; e no modelo (3), uma defasagem da variável dependente, o que torna o modelo dinâmico, havendo a necessidade de estimá-lo pelo método dos momentos generalizados, tendo em vista que a estimação por mínimos quadrados ordinários, ou mesmo por efeitos fixos, traria resultados inconsistentes.

Os efeitos temporais não se mostraram relevantes em nenhum dos três modelos. Já a relevância dos efeitos fixos pode ser observada pela mudança de sinal em algumas variáveis do modelo. Por fim, o componente dinâmico também se mostrou relevante, tendo em vista a alta significância do coeficiente da variável defasada dependente.

Quanto aos resultados obtidos para as variáveis do modelo 3, alguns são bastante interessantes, uma vez que diferem do que seria esperado, pelo menos a princípio. Se as vendas e o fluxo de caixa defasado apresentam coeficiente positivo, indicando que há um efeito acelerador para o investimento e há relevância de variáveis financeiras (lucros + depreciação) na determinação do investimento, o mesmo não ocorre com essas variáveis no período $t$, o que significa que o aumento das vendas concorre com os investimentos fixos e exige o uso de recursos na produção.

$\mathrm{O}$ sinal negativo do capital circulante líquido demonstra que investimentos em ativos fixos e em ativos circulantes são decisões concorrentes. Ao aumentar o investimento em ativos fixos, recursos circulantes são usados para o financiamento. Da mesma maneira, ao aumentar as vendas, os investimentos fixos são reduzidos e as firmas precisam deslocar recursos do capital circulante para as operações produtivas de curto prazo. Segundo a Tabela 4, a queda do cash flow foi compensada com maior redução do capital circulante líquido, que se apresentou mais importante do que os financiamentos de longo prazo. Com essa característica, as firmas de capital aberto 
podem estar ilustrando em outra escala o que acontece com pequenas e médias firmas no Brasil, que contam com menos opções de financiamento. O uso de capital circulante líquido, conceito de liquidez neste estudo, para a sustentação dos investimentos torna as empresas muito sensíveis às flutuações de demanda e propensas a realizar ajustes nas quantidades, tanto no emprego quanto na produção.

Finalmente, a amostra poderia ser dividida por critérios quantitativos. Preferimos selecionar as empresas pelo grau de liquidez com que se apresentam no mercado de ações e analisá-las em conjunto. São empresas mais procuradas para compor a carteira dos investidores, que buscam pelo menos o retorno de mercado. As informações dessas empresas são bem conhecidas. Dada as condições de incerteza no período, verificamos a predominância dos recursos financeiros de curto prazo das empresas na determinação do investimento independente do quadro de informações e regras de governança da bolsa de valores.

\section{REFERÊNCIAS}

ABEL, A. B. Optimal investment under uncertainty. American Economic Review, v. 73, p. 228-233, 1983.

ABEL, A. B.; EBERLY, C. J. The effects of uncertainty and irreversibility on capital accumulation. Journal of Monetary Economics, v. 44, p. 339-377, 1999.

ANDERSON, W. H. L. Corporate finance, and fixed investment, an econometric study. Boston: Division of Research, Graduate School of Business Administration, Harvard University, 1964.

BAUMANN, R. (Org.). Brasil: uma década em transição. Rio de Janeiro: Ed. Campus, 2000.

BERNANKE, B.; CAMPBEL, J.; WHITED, T. U. S. Corporate leverage: developments in 1987 and 1988. Brooking Paper of Economic Activity, v. 1, p. 255-286, 1990.

BIELSCHOWSKY, R. (Org.). Investimentos e reformas no Brasil: indústria e infraestrutura nos anos 1990. Brasília: IPEA/CEPAL, 2002.

BRUINSHOOFD, A. Corporate investment and financing constraints: connections with cash management. DNB Staff Reports, n. 110, p. 1-96, 2003.

BUTZEN, P.; FUSS, C. Firms' investment and finance decisions: theory and empirical methodology. Cheltenham: Edward Elgar, 2003.

CABALLERO, R. J. On the sign of the investment: uncertainty relationship. American Economic Review, v. 81, p. 279-288, 1991.

CHIRINKO, R. S. Business fixed investment spending: modeling strategies, empirical results, and policy implications. Journal of Economic Literature, v. 31, p. 1.875-1.911, 1993. 
CLEARY, S. The relationship between firm investment and financial status. Journal of Finance, v. 54, n. 2, p. 673-692, 1999.

. International corporate investment and the relationship between financial constraint measures. Journal of Banking \& Finance, Amsterdã, v. 30, n. 5, p. 1.559-1.580, 2006.

CLEARY, S.; POVEL, P.; RAITH, M. The U-shaped investment curve: theory and evidence. Simon Business School Working Paper, N. FR 03-32 SSRN, 2004. Disponível em: <http:// ssrn.com/abstract=47092>. Acesso em 10 de maio de 2009.

DIXT, A.; PINDYCK, R. Investment under uncertainty. Princeton: Princeton University Press, 1994.

EICHENGREEN, B. Crises financeiras: análise, prevenção e gestão. Rio de Janeiro: Ed. Campus, 2003.

ELLIOT, J. W. Teories of Corporate Investment Behavior Revisited. American Economic Review, v. 63, n. 1, 1973.

FAZZARI, S. M.; HUBBARD, G.; PETERSEN, B. Financing constraints and corporate investment. Brookings Papers on Economic Activity, n. 1, p. 141-95, 1988.

Investment cash flow sensitivities are useful: a comment on Kaplan and Zingales. Quarterly Journal of Economics, v. 125, n. 2, p. 695-705, 2000.

FAZZARI, S. M.; MOTT, T. L. The investment theories of Kalecki and Keynes: an empirical study of fir data, 1970-1982. Journal of Post Keynesian Economics, v. 9, n. 2, p. 171-187, $1986 / 1987$.

FAZZARI, S. M.; PETERSON, B. Working capital and fixed investment: new evidence on finance constraints. The Rand Journal of Economics, v. 24, n. 3, p. 328-42, 1993.

GÉRARD, M.; VERSCHUEREN, F. “Capital market imperfections and investment: where do we stand?” In: BUTZEN, P.; FUSS, C. Firms' investment and finance decisions: theory and empirical methodology. Cheltenham: Edward Elgar, 2003. p. 59-77.

HOSHI, T.; KASHYAP, A. K.; SCHARFSTEIN, D. Corporate structure, liquidity, and investment: evidence from Japanese industrial groups. Quarterly Journal of Economics, v. 106, p. 33-60, 1991.

HOVAKIMIAN, G.; TITMAN, S. Corporate investment with financial constraints: sensitivity of investment to funds from Voluntary Asset Sales. Journal of Money, Credit and Banking, v. 38, n. 2, p. 357-374, 2006.

HUBBARD, G. Capital-market imperfections and investment. Journal of Economic Literature, v. 36, p. 193-225, 1998.

HUBBARD, R. G.; KASYAP, A. K.; WHITED, T. M. Internal finance and firm investment. Journal of Money, Credit, and Banking, v. 27, n. 3, p. 683-701, 1995.

JENSEN, M. C.; MECKLING, W. H. Theory of the firm: managerial behavior, agency costs and ownership structure. Journal of Financial Economics, v. 6, p. 305-360, 1976. 
JORGENSON, D. W. Econometric studies of investment behavior: a survey. Journal of Economic Literature, v. 9, n. 4, p. 1.111-1.146, 1971.

JORGENSON, D. W.; HUNTER, J.; NADIRI, M. A comparison of alternative econometric models of corporate investment behavior. Econometrica, v. 38, n. 2, p. 213-224, 1970.

JORGENSON, D. W.; SIEBERT, C. D. A comparison of alternative theories of corporate investment behavior. The American Economic Review, v. 58, n. 4, p. 681-712, 1968.

JORGENSON, D. W.; STEPHENSON, J. A. Investment behavior. Econometrica, v. 35, n. 2, p. 169-220, 1967.

Anticipation and investment behavior in U.S. manufacturing, 1947 - 1960. Journal of the American Statistical Association, v. 69, n. 325, p. 67-89, 1969.

KAPLAN, S.; ZINGALES, L. Do investment cash-flow sensitivities provide useful measures of financing constraints. Quarterly Journal of Economics, v. 122, n. 1, p. 169-215, 1997.

. Investment cash flow sensitivities are not valid measures of financing constraints. Quarterly Journal of Economics, v. 115, n 2, p. 707-712, 2000.

MEYER, J.; GLAUBER, R. Investment decisions, economic forecasting, and public policy: division of research, graduate school of business administration. Boston: Harvard University, 1964.

MEYER, J.; KUH, E. The investment decision. Cambridge: Harvard University Press, 1957.

MODIGLIANI, F.; MILLER, M. H. The cost of Capital, corporation finance and the theory of investment. The American Economic Review, v. 48, n. 3, p. 162-197, 1958.

. Dividend policy, growth, and the valuation of shares. The Journal of Business, v. 34, n. 4 , p. $411-433,1961$.

RADALET, S.; SACHS, J. “O despontar da crise financeira do leste europeu”. In: KRUGMAN, P. Crises monetárias. São Paulo: Makron Books, 2001. p. 121-189.

SCHALLER, H. Asymmetric information, liquidity constraints, and Canadian investment. Canadian Journal of Economics, v. 26, n. 3-4, p. 552-574, 1993. 